\title{
QUANTIFICAÇÃO DE NITRATO E NITRITO EM LINGÜIÇAS DO TIPO FRESCAL ${ }^{1}$
}

\author{
Milyan Jorge de OLIVEIRA², Wilma M. C. ARAÚJO3 , Luiz Antônio BORGO4
}

\section{RESUMO}

O objetivo do trabalho foi quantificar o teor de nitrato e nitrito de sódio em amostras de lingüiças frescal de frango e pernil, em quatro lotes distintos de sete produtores. O delineamento experimental foi inteiramente ao acaso, com tratamentos dispostos no esquema fatorial 7x4. Aos dados obtidos aplicou-se análise de variância, para obter o quadrado médio do resíduo. Para verificar a homogeneidade dos experimentos utilizou-se o teste de Hartley. Prosseguiu-se à análise conjunta para comparar os dois tipos de lingüiça. Aplicou-se o esquema fatorial 7x4x2 e obteve se o F significativo. Aplicou-se o teste de Tukey ao nível de $1 \%$ de significância. Os resultados indicam que as amostras de lingüiça frescal de frango apresentaram valores entre 7,6 e 312,5 ppm para a fração de nitrato de sódio e valores entre 1,2 e 221 ppm para a fração de nitrito; para as amostras de lingüiça frescal de pernil, os teores obtidos estiveram entre 8,6 e 363,6 ppm para a fração de nitrato e entre 0,6 a 162,2 ppm para a de nitrito. Entre os lotes de lingüiça de frango, a variação esteve entre 7,6 e 312,5 ppm para a fração de nitrato e entre 1,2 e 221 ppm para a de nitrito; as amostras de lingüiça frescal de pernil apresentaram valores de 100 a 104,3 ppm para nitrato e de 0,6 a 162,2 ppm para nitrito. 7,1\% das amostras estavam em desacordo com a legislação.

Palavras-chave: nitrito, nitrato, embutidos cárneos, toxicologia.

\section{SUMMARY}

QUANTIFICATION OF NITRATE AND NITRITE IN FRESH SAUSAGE. The objective of this study was to quantify the nitrate and the nitrite level of four distinctive lots of pork leg and chicken sausages of seven different producers. The experimental outline was at random with a factorial treatment of $7 \times 4$. To the obtained data, a variance analysis was applied in order to reach the medium square of the residue. In order to verify homogeneity of the experiments, the Hartley test was used. It was followed by the joint analysis to compare the two types of sausages. The factorial schema of $7 \times 4 \times 2$ was applied to obtain the significant F. The Tukey test was also conducted with a $1 \%$ significance level. The results indicated that the samples of chicken fresh sausages showed levels between 7.6 to $312.5 \mathrm{ppm}$ for the sodium nitrate fraction and levels between 1.2 to $221 \mathrm{ppm}$ for the nitrite fraction. For the samples of pork leg fresh sausages, the obtained values were between 8.6 to $363.6 \mathrm{ppm}$ for nitrate and between 0.6 to $162.2 \mathrm{ppm}$ for nitrite. Among the chicken sausage lots, the variation ranged from 7.6 to $312.5 \mathrm{ppm}$ for the nitrate fraction and from 1.2 to $221 \mathrm{ppm}$ for the nitrite. The pork leg sausage samples showed values from 100 to $104,3 \mathrm{ppm}$ for nitrate and from 0.6 to 162.2 for nitrite. $7.1 \%$ of the samples were in discordance to the legislation.

Keywords: nitrite, nitrate, toxicology.

\section{1 - INTRODUÇÃO}

As carnes são alimentos perecíveis e apresentam vida de prateleira variável em função das condições de armazenamento. Desde a Antigüidade, o homem sempre buscou preservar suas características de qualidade para manter a provisão de alimentos, o desenvolvimento e a conservação da espécie, originando-se, assim, processos e tecnologias de transformação, inicialmente rudimentares e atualmente controláveis por padrões tecnológicos para manter a qualidade dos produtos.

A fabricação de embutidos propicia o aumento da vida de prateleira das carnes, bem como diversifica a oferta de derivados [29]. Embutidos cárneos são definidos como "produtos elaborados com carnes ou outros tecidos animais comestíveis, curados ou não, defumados e dessecados ou não, tendo como envoltório natural tripas, bexigas ou outras membranas animais ou envoltório plástico apropriado" [14]. As diferenças climáticas condicionam as principais características dos embutidos e se destacam entre os fatores que contribuem para sua diversificação.

\footnotetext{
${ }^{1}$ Recebido para publicação em 12/11/2004. Aceito para publicação em 29/09/2005 (001436).

${ }^{2}$ Dissertação de Mestrado apresentada ao Departamento de Nutrição Humana/UnB, e-mail: milyan@hotmail.com.

${ }^{3}$ Departamento de Nutrição da Universidade de Brasília, e-mail: wilma. araujo@terra.com.br.

${ }^{4}$ Faculdade de Agronomia e Medicina Veterinária da Universidade de Brasília,e-mail:borgo@unb.br.
}

Os produtos frescais tiveram sua origem nos países frios do norte europeu; produtos cozidos, defumados e semisecos são originários da Alemanha; produtos secos foram desenvolvidos principalmente nos países de verão quente do sul da Europa [6].

No Brasil, os embutidos crus, elaborados a partir de carne de suínos, bovinos ou aves, não apresentam padrões de identidade definidos, verificando-se uma grande variação na qualidade final, que envolvem aspectos referentes à apresentação, à composição centesimal e ao valor nutritivo [5].

Dados apresentados em 1998 indicam que aproximadamente mil estabelecimentos industriais brasileiros estão registrados no Ministério da Agricultura, Pecuária e Abastecimento (MAPA) ou nas Secretarias Estaduais da Agricultura e são responsáveis por um volume de produção equivalente a 1 milhão e 200 mil toneladas de embutidos. Deste volume, a produção de lingüiça do tipo frescal ocupa o primeiro lugar [29].

Segundo a legislação, lingüiça "é o produto cárneo industrializado obtido de carnes de animais de açougue, adicionado ou não de tecidos adiposos, ingredientes, embutido em envoltório natural ou artificial e submetido ao processo tecnológico adequado" [3].

A lingüiça do tipo frescal destaca-se dentre os produtos cárneos embutidos por sua aceitação e comercialização. O processo de produção utiliza carnes de animais de açougue, 
adicionadas ou não de tecidos adiposos, e o processamento pode ocorrer em estabelecimentos de micro, pequeno, médio e grande porte. Ao processo, agregam-se aditivos utilizados para melhorar as características sensoriais do produto.

De acordo com a Legislação Brasileira para embutidos não submetidos ao cozimento, como é o caso da lingüiça frescal, é permitida a adição de água ou gelo até o máximo de $3 \%$ na formulação, calculada sobre o total dos componentes e com a finalidade de facilitar a trituração e homogeneização da massa [16]. A lingüiça do tipo frescal apresenta, como características físico-químicas, umidade máxima de $70 \%$, gordura máxima de $30 \%$ e proteína mínima de $12 \%$ [3]. O processo requer adição de sais de cura, recurso que permitirá ao alimento produzido em escala industrial atingir os parâmetros característicos de qualidade sensorial - sabor, cor, aroma e textura e a preservação do produto [26].

Sais de cura, como nitrato e nitrito de sódio e de potássio, são largamente utilizados como aditivos alimentares no processamento de produtos cárneos. Os sais de nitrito, além de conservarem a carne contra a deterioração bacteriana, são fixadores de cor e agentes de cura. Seus efeitos adversos são representados principalmente pela metamioglobina tóxica e pela formação de nitrosaminas. Seu uso é discutível dada a possibilidade de originar compostos nitrosos de ação carcinogênica [13].

O uso destes aditivos é altamente discutido em virtude da possibilidade de originarem compostos nitrosos de ação carcinogênica, como a N-nitrosodimetilamina e a monometilnitrosamina [19]. O nitrito é bem mais tóxico que o nitrato. Produz, principalmente, vasodilatação e relaxamento da musculatura lisa em geral, além da formação de metahemoglobina. A dose letal para adultos está em torno de 1 grama. Em doses mais baixas, os sintomas são enrubescimento da face e extremidades, desconforto gastrointestinal e dor de cabeça. Em doses tóxicas um pouco mais elevadas observam-se cianose, náusea, vômitos, dores abdominais e colapso [21].

Os compostos N-nitrosos são conhecidos como potentes cancerígenos em várias espécies, inclusive primatas, e a exposição humana ocorre pela inalação, ingestão de nitrosaminas pré-formadas ou pela nitrosação endógena [22, 12]. Trabalhos de revisão [1, 2, 23] sobre a presença de nitrosaminas em alimentos ressaltam as atividades mutagênicas e teratogênicas desses compostos. A ingestão de nitritos deve ser bem restrita, principalmente por crianças, pois, uma vez absorvido, o nitrito pode agir sobre a hemoglobina e produzir a metamioglobina, impedindo que ela exerça a função normal de transportar o oxigênio [11].

Desde 1968 a agência estadunidense - Food and Drug Administration (FDA) - se preocupa com a presença de nitrosaminas nos alimentos e, juntamente com a indústria norte-americana de alimentos, despende grandes esforços para reduzir os níveis de nitrosaminas e encontrar substitutos para o nitrito [8, 20, 24]. A legislação brasileira vigente prevê limites máximos de 0,015 g/100 g e 0,03 g/100 g, respectivamente para nitrito e nitrato de sódio, para carnes e produtos cárneos, denominados estes produtos como conservantes [4].

Trabalhos apontam ainda a possível interação de tais substâncias com componentes dos alimentos, no processamento ou no metabolismo, que promovem, por sinergismo, a formação de componentes de maior toxicidade, ou, por antagonismo, substâncias que podem reduzir sua toxicidade [30]. Para alguns autores [9], é imprescindível estabelecer medidas preventivas substanciais para efetivar o controle de qualidade e a vigilância sanitária objetivando minimizar os efeitos tóxicos causados pelos aditivos alimentares, especialmente em grupos mais suscetíveis: crianças, idosos, gestantes e enfermos.

O objetivo deste trabalho foi quantificar os teores de nitrato e nitrito de sódio em lingüiças do tipo frescal e comparar os valores encontrados com os preconizados pela legislação.

\section{2 - MATERIAL E MÉTODOS}

Foram coletadas aleatoriamente, entre novembro/2001 e julho/2002, 56 amostras de lingüiça frescal de frango e de pernil, perfazendo um total de sete produtores e quatro lotes. As análises para quantificação dos teores de nitrato e nitrito foram realizadas em triplicata, de acordo com os Métodos Analíticos Oficiais para Controle de Produtos de Origem Animal e seus Ingredientes [10].

Os dados obtidos foram analisados estatisticamente. Foram realizados dois experimentos independentes, um para lingüiça frescal de frango e outro para lingüiça frescal de pernil, para verificar se os teores de nitrato e nitrito variavam em função do lote e do produtor.

Para cada experimento, o delineamento experimental empregado foi inteiramente ao acaso, com os tratamentos dispostos no esquema fatorial $7 \times 4$, referente a 7 produtores e 4 lotes. Os dados obtidos foram submetidos à análise de variância para obtenção do quadrado médio do resíduo, para verificar a homogeneidade dos experimentos, pelo teste de Hartley.

Comprovada a homogeneidade entre os experimentos, prosseguiu-se com a análise conjunta para poder comparar os dois tipos de lingüiça frescal. Na análise conjunta, os tratamentos ficaram dispostos no esquema fatorial $7 \times 4 \times 2$, referente a 7 produtores, 4 lotes e 2 tipos de lingüiça.

Após obter o F significativo, a análise prosseguiu com a aplicação do teste de Tukey ao nível de $1 \%$ de significância, para as comparações múltiplas entre as médias dos teores de nitrato e nitrito. Todas as análises foram realizadas pelo programa Statistical Analysis System (SAS) for Windows [17].

\section{3 - RESULTADOS E DISCUSSÃo}

Pela análise de variância, foi possível observar que existem diferenças estatísticas significativas entre os teores de nitrato e nitrito quando avaliados em termos de produ- 
tor, de lote, de produto e de suas interações. Desta forma, a análise estatística prosseguiu com a aplicação do teste de Tukey para a comparação das médias para a interação tripla, verificando as diferenças entre os lotes para cada produtor e entre os produtores para cada lote em cada tipo de lingüiça frescal.

Pela Tabela 1, observa-se, com relação às amostras de lingüiça frescal de frango, que o teor de nitrato, no primeiro lote, diferiu entre todos os produtores: a menor concentração $(8,6 \mathrm{ppm})$ foi encontrada para o produtor P3, sendo que o produto obtido por P1 apresentou maior concentração de nitrato (137,5 ppm). Para o segundo lote, verificou-se não haver diferença estatística significativa entre o teor de nitrato dos produtos elaborados pelo P1 e P3, que diferiram dos teores observados nas amostras dos demais produtores.

Ainda com relação ao lote 2 , os produtos provenientes dos produtores 2, 4, 5, 6 e 7 apresentaram valores entre 35,2 ppm e 196,9 ppm, propiciando divergências de até 459\% de teores de nitrato entre os produtos. No terceiro lote, as amostras analisadas para os sete produtores também apresentaram divergências entre os resultados obtidos. Os produtos elaborados pelo P1 apresentaram maior teor de nitrato (138,3 ppm), seguido, respectivamente, em ordem decrescente pelos produtores P5, P2, P6, P7, P4 e P3. Observou-se ainda que no quarto lote ocorreu maior variação entre os teores de nitrato. Os produtos fabricados pelo P5 apresentaram maior teor de nitrato - 312,5 ppm - e os produtos do P3 foram os que apresentaram teor mais baixo - 7,6 ppm. Apesar das diferenças encontradas para o teor de nitrato destas amostras, verifica-se que os resultados estão de acordo com os parâmetros apresentados na legislação vigente [4].

Com relação aos dados apresentados na Tabela 2 , observa-se que o teor de nitrito, no primeiro lote, diferiu entre todos os produtores; apresentou variações entre 2,4 ppm (P5) e 221 ppm (P1), que corresponde a uma variação de 8957\%. No segundo lote, verificou-se não haver diferença estatística significativa entre os teores de nitrito nos produtos fabricados pelos P2 e P5, que diferiram dos demais, que também diferiram entre si. Para esse mesmo lote, as amostras do P4 apresentaram maior teor de nitrito, enquanto as amostras dos P2 e P5 apresentaram menores concentrações.

No terceiro lote, o teor de nitrito diferiu entre todos os produtores: P1 apresentou o maior teor de nitrito; os demais, P3, P4, P2, P6, P7, P5, respectivamente, apresentaram teores decrescentes de nitrito. Estima-se uma variação em torno de 1689\%. Para o quarto lote, observou-se que há diferença estatística significativa entre todos os produtores, apresentando uma faixa de 3,7 ppm (P7) e 83,6 ppm (P5), correspondente a $2164 \%$. Apesar das diferenças estatísticas significativas encontradas para o teor de nitrito destas amostras, verificou-se que os resultados não estão de acordo com os parâmetros apresentados na legislação vigente para P1 [4].

Sobre os resultados das amostras de lingüiça frescal de pernil, a Tabela 3 indica que o teor de nitrato, no primeiro lote, apresentou diferença estatística significativa entre todos os produtores. Nesse lote, o menor teor de nitrato encontrado

TABELA 1 - Teores de nitrato (ppm) para os 4 lotes de lingüiça frescal de frango em função do produtor analisado (DMS*=1,31)

\begin{tabular}{|c|c|c|c|c|}
\hline & Lote 1 & Lote 2 & Lote 3 & Lote 4 \\
\hline Produtor $1-\mathrm{P} 1$ & $137,5 a$ & $138,6 \mathrm{a}$ & $138,3 \mathrm{a}$ & $137,4^{a}$ \\
\hline Produtor 2 - P2 & $60,1 b$ & $196,9 b$ & $61,2 b$ & $89,5 b$ \\
\hline Produtor 3 - P3 & $8,6 c$ & 137,5 a & $7,7 \mathrm{c}$ & $7,6 c$ \\
\hline Produtor 4 - P4 & $13 d$ & $181,7 \mathrm{c}$ & $12,4 d$ & $162,3 d$ \\
\hline Produtor 5 - P5 & $84 \mathrm{e}$ & $48,8 d$ & $82,7 e$ & $312,5 \mathrm{e}$ \\
\hline Produtor 6 - P6 & $46,7 f$ & $46,5 \mathrm{e}$ & $45,8 f$ & $63,4 f$ \\
\hline Produtor 7 - P7 & $45,2 \mathrm{~g}$ & $35,2 f$ & $44,5 \mathrm{~g}$ & $52,1 \mathrm{~g}$ \\
\hline
\end{tabular}

*(DMS= diferença mínima significativa)

TABELA 2 - Teores de nitrito (ppm) para os quatro lotes de lingüiça frescal de frango em função do produtor analisado (DMS=0,58)

\begin{tabular}{|c|c|c|c|c|}
\hline & Lote 1 & Lote 2 & Lote 3 & Lote 4 \\
\hline Produtor 1 - P1 & $221^{a}$ & $5,95 a$ & $220,7 a$ & $46,2 \mathrm{a}$ \\
\hline Produtor 2 - P2 & $41 b$ & $1,9 b$ & $46,4 b$ & $53,1 b$ \\
\hline Produtor 3 - P3 & $92,3 c$ & $5,1 \mathrm{c}$ & $91,1 \mathrm{c}$ & $78,9 \mathrm{c}$ \\
\hline Produtor 4 - P4 & $57,9 d$ & $91,8 d$ & $57,1 d$ & $42,6 d$ \\
\hline Produtor 5 - P5 & $2,4 e$ & $1,6 b$ & $1,2 \mathrm{e}$ & $83,6 e$ \\
\hline Produtor 6 - P6 & $26,1 f$ & $25,6 e$ & $25,7 f$ & $44,1 f$ \\
\hline Produtor 7 - P7 & $19,1 \mathrm{~g}$ & $29,1 \mathrm{f}$ & $18,8 \mathrm{~g}$ & $3,7 \mathrm{~g}$ \\
\hline
\end{tabular}

*(DMS= diferença mínima significativa)

TABELA 3 - Teores de nitrato (ppm) para os 4 lotes de lingüiça frescal de pernil em função do produtor analisado (DMS=1,31)

\begin{tabular}{|c|c|c|c|c|}
\hline & Lote 1 & Lote 2 & Lote 3 & Lote 4 \\
\hline Produtor $1-\mathrm{P} 1$ & $100 a$ & $100,4 a$ & $100,7 a$ & $104,3^{a}$ \\
\hline Produtor 2 - P2 & $28,9 b$ & $9,1 b$ & $28,8 b$ & $136,4 b$ \\
\hline Produtor 3 - P3 & $10,2 c$ & $45,6 c$ & $8,6 c$ & $10,1 \mathrm{c}$ \\
\hline Produtor 4 - P4 & $324,3 d$ & $291,8 d$ & $335,9 d$ & $363,6 d$ \\
\hline Produtor 5 - P5 & $15 e$ & $17,1 \mathrm{e}$ & $14,2 \mathrm{e}$ & $120 \mathrm{e}$ \\
\hline Produtor 6 - P6 & $44 f$ & $43,7 f$ & $43,1 f$ & $43,9 f$ \\
\hline Produtor $7-\mathrm{P} 7$ & $81,1 \mathrm{~g}$ & $142,2 \mathrm{~g}$ & $80,6 \mathrm{~g}$ & $189,9 \mathrm{~g}$ \\
\hline
\end{tabular}

*(DMS= diferença mínima significativa) 
foi nos produtos fabricados pelo P3 (10,2 ppm) e o maior teor de nitrato observado foi nos produtos fabricados pelo P4 (324,3 ppm), com diferença percentual de 3091,4\%. No segundo lote houve diferença estatística significativa para o teor de nitrato entre todos os produtores. As maiores concentrações foram apresentadas respectivamente nos produtos fabricados pelos P4, P7 e P1. Entre os valores máximo e mínimo, a diferença foi de 3106,7\%.

Observou-se, ainda no lote 3 , uma grande variação $(3788,1 \%)$ entre os teores de nitrato utilizados nos produtos fabricados pelos diferentes produtores. O teor diferiu entre todos os produtores e atingiu valores entre 8,6 ppm (P3) e 335,9 ppm (P4). No quarto lote, constatou-se que os teores de nitrato também apresentaram uma grande variação: de 10,1 ppm (P3) a 363,6 ppm (P4), o que significa uma oscilação em torno de 3496,9\%. Comparando-se o teor de nitrato destas amostras com os preconizados pela legislação vigente, verificou-se que os resultados não estão de acordo para os lotes 1, 3 e 4 do produtor P4 [4].

Embora sejam inegáveis os benefícios alcançados com o uso de aditivos em alimentos, a preocupação quanto aos riscos toxicológicos potenciais decorrentes da ingestão diária destas substâncias químicas é incontestável. O potencial tóxico de um aditivo depende de propriedades intrínsecas ao composto químico, de seus metabólitos e de sua capacidade de acúmulo no organismo, que com o decorrer dos anos pode influenciar no aparecimento de doenças crônico-degenerativas [28].

A Tabela 4 apresenta os teores de nitrito (ppm) para os 4 lotes de lingüiça frescal de pernil. Os resultados obtidos para as amostras analisadas do P1 (lotes 1, 2, 3 e 4) apresentaram variação de $9910,7 \%$ - de 1,7 ppm a 162,2 ppm. Para os produtores P2, P3 e P4 as variações foram de 1,7 ppm a $57,8 \mathrm{ppm}$; $2,1 \mathrm{ppm}$ a $5 \mathrm{ppm}$ e $7,8 \mathrm{ppm}$ a $30,4 \mathrm{ppm}$, respectivamente, sendo que para os produtos elaborados pelos produtores P5, P6 e P7 os intervalos foram de 4ppm a 41,7 ppm; 0,6 ppm a 30,2 ppm e 1,8 ppm a 8 ppm, respectivamente, para as concentrações de nitrito.

O teor de nitrito para as amostras do primeiro lote diferiu estatisticamente para todos os produtores e foi superior ao das demais amostras do segundo, terceiro e quarto lotes, especialmente com relação às dos lotes 2 e 4 . As amostras do lote 2 apresentaram variações de 1,7 ppm (P1) a 30,4 ppm (P4), correspondendo a variações de até $1707 \%$. Para os lotes 3 e 4, respectivamente, foram observadas também oscilações entre 2,1 ppm e 157,9 ppm e 0,6 ppm e 57,8 ppm na concentração de nitrito.

A Tabela 5 apresenta os teores de nitrato encontrados para os sete produtores de lingüiça frescal de frango. Observa-se que as amostras elaboradas pelos produtores P1, P6 e P7, para os quatro lotes não apresentaram grandes oscilações, sendo P1 o único que não apresentou diferença estatística significativa para os quatro lotes produzidos. Para o produtor $\mathrm{P} 1$, as variações foram de $13,5 \mathrm{ppm}$ a 138,6 ppm; para o produtor P6 de 45,8 ppm a 63,4 ppm; sendo que para o produtor P7 a variação foi de 35,2 ppm a 52,1 ppm. Verificou-se um certo grau de padronização quanto ao uso deste aditivo químico, apesar das diferenças quanto às concentrações utilizadas pelos produtores.

Os produtos elaborados pelo produtor P2, nos quatro lotes analisados, apresentaram variações entre 60,1 ppm a 196,9 ppm de nitrato. Para o produtor P3, as oscilações foram de $1707 \%$ (7,6 ppm a 137,5 ppm); para o produtor $\mathrm{P} 4,1363 \%$ (12,4 ppm a 181,7 ppm) e para o produtor P5, $540 \%$ (48,8 ppm a 312,5 ppm).

Pelos dados apresentados na Tabela 6, não se observou diferença estatística significativa para o teor de nitrito entre

TABELA 4 - Teores de nitrito (ppm) para os 4 lotes de lingüiça frescal de pernil em função do produtor analisado $(\mathrm{DMS}=0,58)$

\begin{tabular}{lcccc}
\hline & Lote 1 & Lote 2 & Lote 3 & Lote 4 \\
\hline Produtor 1-P1 & $162,2 \mathrm{a}$ & $1,7 \mathrm{a}$ & $157,9 \mathrm{a}$ & $43,8^{\mathrm{a}}$ \\
Produtor 2 - P2 & $31,9 \mathrm{~b}$ & $1,7 \mathrm{a}$ & $29,4 \mathrm{~b}$ & $57,8 \mathrm{~b}$ \\
Produtor 3 - P3 & $3,1 \mathrm{c}$ & $3,8 \mathrm{~b}$ & $2,1 \mathrm{c}$ & $5 \mathrm{c}$ \\
Produtor 4 - P4 & $8,1 \mathrm{~d}$ & $30,4 \mathrm{c}$ & $7,8 \mathrm{~d}$ & $20,3 \mathrm{~d}$ \\
Produtor 5 - P5 & $5 \mathrm{e}$ & $4,6 \mathrm{~d}$ & $4 \mathrm{e}$ & $41,7 \mathrm{e}$ \\
Produtor 6 - P6 & $30,2 \mathrm{f}$ & $28,7 \mathrm{e}$ & $28,6 \mathrm{f}$ & $0,6 \mathrm{f}$ \\
Produtor 7 - P7 & $6,1 \mathrm{~g}$ & $1,8 \mathrm{f}$ & $5,8 \mathrm{~g}$ & $8 \mathrm{~g}$ \\
\hline
\end{tabular}

*(DMS $=$ diferença mínima significativa)

TABELA 5 - Teores de nitrato (ppm) para os sete produtores de lingüiça frescal de frango em função do lote analisado (DMS=1,18)

\begin{tabular}{lccccccc}
\hline & $\mathbf{P 1}$ & $\mathbf{P 2}$ & $\mathbf{P 3}$ & $\mathbf{P 4}$ & $\mathbf{P 5}$ & P6 & P7 \\
\hline Lote 1 & $137,5^{\mathrm{a}}$ & $60,1 \mathrm{a}$ & $8,6 \mathrm{a}$ & $13,0 \mathrm{a}$ & $84 \mathrm{a}$ & $47 \mathrm{a}$ & $45,2 \mathrm{a}$ \\
Lote 2 & $138,6 \mathrm{a}$ & $196,9 \mathrm{~b}$ & $137,5 \mathrm{~b}$ & $181,7 \mathrm{~b}$ & $48,8 \mathrm{~b}$ & $46,5 \mathrm{a}$ & $35,2 \mathrm{~b}$ \\
Lote 3 & $138,3^{\mathrm{a}}$ & $61,2 \mathrm{a}$ & $7,7 \mathrm{a}$ & $12,4 \mathrm{a}$ & $82,7 \mathrm{c}$ & $45,8 \mathrm{a}$ & $44,5 \mathrm{a}$ \\
Lote 4 & $137,5^{\mathrm{a}}$ & $89,5 \mathrm{c}$ & $7,6 \mathrm{a}$ & $162,3 \mathrm{c}$ & $312,5 \mathrm{~d}$ & $63,4 \mathrm{~b}$ & $52,1 \mathrm{c}$ \\
\hline
\end{tabular}

*(DMS = diferença mínima significativa)

TABELA 6 - Teores de nitrito (ppm) para os sete produtores de lingüiça frescal de frango em função do lote analisado (DMS=0,52)

\begin{tabular}{|c|c|c|c|c|c|c|c|}
\hline & P1 & P2 & P3 & P4 & P5 & P6 & P7 \\
\hline Lote 1 & $221 a$ & $41 a$ & $92,3^{a}$ & $57,9^{a}$ & $2,4 a$ & $26,1 a$ & $19,1 \mathrm{a}$ \\
\hline Lote 2 & $6 b$ & $2 b$ & $5,1 b$ & $91,8 b$ & $1,6 b$ & $25,6 a$ & $29,1 b$ \\
\hline Lote 3 & $220,7 a$ & $46,4 c$ & $91,1 \mathrm{c}$ & $57,1 \mathrm{c}$ & $1,2 b$ & $25,7 a$ & $18,8 a$ \\
\hline Lote 4 & $46,2 c$ & $53,1 d$ & $79 d$ & $42,6 d$ & $83,6 c$ & $44,1 b$ & $3,7 c$ \\
\hline
\end{tabular}

*(DMS = diferença mínima significativa) 
as amostras do produtor P1, nos lotes 1 e 3 . Para os lotes 2 e 4 , a variação foi de $676,6 \%$. Para os produtores P2, P3 e P4, verificou-se diferença estatística significativa entre as amostras de todos os lotes. As maiores variações foram de 2 ppm a 53,1 ppm de nitrito, de 5,1 ppm a 92,3 ppm e 42,6 ppm a 91,8 ppm, respectivamente.

Observou-se ainda não existir diferença estatística significativa entre os lotes 2 e 3 , que diferiram dos lotes 1 e 4, para o produtor P5. Verificou-se que as amostras apresentaram concentrações variáveis entre 1,2 ppm e 83,6 ppm de nitrito. Para o produtor P6, não foi observada diferença estatística significativa entre os teores de nitrito observados nas amostras provenientes dos lotes 1, 2 e 3 . Os teores variaram de 25,6 ppm a 44,1 ppm. Quanto ao produtor P7, observou-se uma variação de 689\% (3,7 ppm a 29,1 ppm), não havendo diferença estatística significativa entre os lotes 1 e 3 .

Com respeito à adição de sais de nitrato na produção de lingüiça frescal de pernil, observou-se, para o produtor $\mathrm{P} 1$, que não houve diferença estatística significativa entre o primeiro, o segundo e o terceiro lotes, conforme Tabela 7. Somente o quarto lote diferiu estatisticamente dos demais, apresentando a maior concentração do aditivo (104,3 ppm). Entre a menor e a maior concentração do aditivo, nos quatro lotes, a variação observada foi de $4,3 \%$. Para o P4, verificou-se que houve diferença estatística significativa entre os lotes 1, 2, 3 e 4 .

Observou-se, também, que foram as amostras que apresentaram maiores teores de nitrato; no lote 4, os produtos apresentaram valores acima do limite máximo permitido pela legislação (300 ppm). Embora sejam inegáveis os benefícios alcançados com o uso deste aditivo em alimentos, o potencial tóxico depende de propriedades intrínsecas ao composto químico e seus metabólitos e também de sua capacidade de acúmulo no organismo, podendo causar, ao longo da vida, doenças crônico-degenerativas [28]. As amostras dos lotes 1 e 3 dos produtores P1, P2, P3, P5, P6 e P7 não apresentaram diferença estatística significativa para um mesmo produtor quanto ao teor de nitrato, apesar da diferença quantitativa obtida analiticamente quando comparamos os produtores entre si.
Os resultados atendem aos padrões legais apesar de uma variação de $748,2 \%$ entre o menor e maior teor de nitrato obtido nas análises dos produtos do produtor P5, com exceção do produtor P4 nos lotes 1, 3 e 4. Para o produtor P7, a oscilação é de $135,7 \%$, que corresponde à variação entre 80,6 ppm e 189,6 ppm. Verifica-se que os produtos elaborados pelo produtor P6 foram os únicos a não apresentar diferença significativa entre os lotes.

Semelhantemente aos resultados obtidos para os teores de nitrato nas lingüiças de pernil do tipo frescal analisadas, observou-se a mesma tendência para as concentrações de nitrito (Tabela 8).

Segundo a literatura [7], os teores de nitrato diminuem com o tempo. Como as análises foram feitas com até uma semana de armazenamento das amostras sob refrigeração, divergências nos teores encontrados podem ser atribuídas à conversão do nitrato a nitrito. As amostras dos produtores P1, P2, P3 e P4 apresentam diferença significativa entre todos os lotes. Para o produtor P1 a oscilação entre a menor e a maior concentração de nitrato é de 160,3 ppm, ou seja, de 9553,6\%. Para o produtor P2, as amostras dos lotes 2 e 4 apresentam variações em torno de 3320,7\%. O produtor P3, comparando-se os lotes, é o que apresenta menor diferença significativa entre as amostras, que é de 2,8 ppm, variação de 131,5\%. Para as amostras dos produtores P5, P6, e P7 dos lotes 1, 2, 3 e 4, observa-se que, pelo menos dois lotes de cada um deles, apresentaram teores de nitrito bem próximos, não permitindo estabelecer diferença significativa no teste de Tukey em nível de $1 \%$.

Apesar das diferenças significativas observadas, todas as amostras apresentaram teores de nitrito de acordo com os padrões legais, com exceção do produtor P1 nos lotes 1 e 3. A literatura mostra que, no Brasil, os embutidos crus elaborados a partir de carne de suínos, bovinos ou aves não apresentam padrões de identidade definidos, verificando-se uma grande variação na qualidade final dos produtos [5].

O exame de 50 amostras de embutidos diversos comercializados em Jaboticabal/SP mostrou níveis de nitrito de sódio superiores a 200 ppm em $60 \%$ das salsichas, $50 \%$ das lingüiças frescais, $30 \%$ das mortadelas, $20 \%$ dos pre-

TABELA 7 - Teores de nitrato (ppm) para os sete produtores de lingüiça frescal de pernil em função do lote analisado (DMS=1,18)

\begin{tabular}{lccccccc}
\hline & $\mathbf{P 1}$ & $\mathbf{P 2}$ & $\mathbf{P 3}$ & $\mathbf{P 4}$ & $\mathbf{P 5}$ & $\mathbf{P 6}$ & P7 \\
\hline Lote 1 & $100 \mathrm{a}$ & $28,9 \mathrm{a}$ & $10,2 \mathrm{ac}$ & $324,3 \mathrm{a}$ & $15 \mathrm{a}$ & $44 \mathrm{a}$ & $81,1 \mathrm{a}$ \\
Lote 2 & $100,4 \mathrm{a}$ & $9,1 \mathrm{~b}$ & $45,6 \mathrm{~b}$ & $291,8 \mathrm{~b}$ & $17,1 \mathrm{~b}$ & $43,7 \mathrm{a}$ & $142,2 \mathrm{~b}$ \\
Lote 3 & $100,7 \mathrm{a}$ & $28,8 \mathrm{a}$ & $8,6 \mathrm{a}$ & $335,9 \mathrm{c}$ & $14,2 \mathrm{a}$ & $43,1 \mathrm{a}$ & $80,6 \mathrm{a}$ \\
Lote 4 & $104,3 \mathrm{~b}$ & $136,4 \mathrm{c}$ & $10,1 \mathrm{c}$ & $363,6 \mathrm{~d}$ & $120 \mathrm{c}$ & $43,9 \mathrm{a}$ & $189,6 \mathrm{c}$ \\
\hline
\end{tabular}

*(DMS = diferença mínima significativa)

TABELA 8 - Teores de nitrito (ppm) para os sete produtores de lingüiça frescal de frango em função do lote analisado (DMS =0,52)

\begin{tabular}{|c|c|c|c|c|c|c|c|}
\hline & P1 & P2 & P3 & P4 & P5 & P6 & P7 \\
\hline Lote 1 & $162,2 \mathrm{a}$ & $31,9 \mathrm{a}$ & $3,1 \mathrm{a}$ & $8,1 \mathrm{a}$ & $5 a$ & $30,2 a$ & $6,1 a$ \\
\hline Lote 2 & $1,7 b$ & $1,7 b$ & $3,8 b$ & $30,4 b$ & $4,6 a$ & $28,7 b$ & $1,8 b$ \\
\hline Lote 3 & $157,9 \mathrm{c}$ & $29,4 c$ & $2,1 \mathrm{c}$ & $7,8 \mathrm{c}$ & $4 b$ & $28,6 b$ & $5,8 a$ \\
\hline Lote 4 & $43,8 d$ & $57,8 d$ & $5 d$ & $20,3 d$ & $41,7 \mathrm{c}$ & $0,6 c$ & $8 c$ \\
\hline
\end{tabular}

*(DMS=diferença mínima significativa) 
suntos e $10 \%$ dos salames [25]. Na região metropolitana de São Paulo, foram analisadas 45 amostras de lingüiça do tipo frescal. Os valores encontrados demonstraram que o limite legal foi ultrapassado em $26,67 \%$ das amostras [27]. Em produtos cárneos comercializados no Distrito Federal, foram analisados os teores residuais de nitrato e nitrito e os resultados apontaram níveis acima do valor máximo permitido pela legislação em amostras de lingüiças suína (530 ppm) e de frango (220 ppm) [31].

A análise dos parâmetros físico-químicos de lingüiças tipo frescal, comercializadas no município de Marília/SP, mostrou que em 60 amostras de lingüiça frescal, das quais $10 \%$ eram de produtos inspecionados e $46 \%$ eram de produtos clandestinos, os resultados obtidos ultrapassaram os índices aceitáveis para nitrato. Quanto ao nitrito, em 10\% das lingüiças inspecionadas e também em 10\% dos produtos clandestinos, os valores excederam os limites para nitrito [15]. Em Brasília/DF foram coletadas 14 amostras de lingüiça tipo frescal - 9 amostras de lingüiça suína e 5 de frango. Do total de amostras, 22,43\% (1 suína e 2 de frango) estavam em desacordo com o subitem 8.2.1.1 do Anexo da Portaria n. 1004 [4, 18] que limita o uso de nitrato em 300 ppm e de nitrito em 150 ppm. Em Belo Horizonte/MG, foram analisadas 60 amostras de lingüiça tipo frescal suína; os valores encontrados demonstraram que o limite legal foi ultrapassado em 13,33\% dos produtos com inspeção; em 3,23\% das lingüiças suínas sem inspeção; em $23,33 \%$ das lingüiças mistas com inspeção e em $6,67 \%$ das lingüiças mistas sem inspeção [5].

Comparando-se os resultados deste trabalho com os apresentados na literatura, observa-se que a produção de embutidos cárneos industrializados crus apresenta variações em suas composições, o que compromete a qualidade e a padronização dos produtos. Além disso, quanto ao uso dos aditivos, é importante ressaltar que $7,1 \%$ das amostras de lingüiça de frango e de pernil apresentaram limites acima do que preconiza a legislação. Estes resultados sugerem a necessidade de um controle mais rigoroso por parte dos órgãos oficiais de inspeção a fim de evitar riscos à saúde pública.

\section{4 - CONCLUSÕES}

Dos resultados obtidos, é possível concluir que há uma grande variação nos teores de nitrato e nitrito entre as amostras dos produtos analisados; tais diferenças também prevalecem entre os lotes de um mesmo produtor; a maioria dos valores obtidos está de acordo com a legislação vigente; porém $7,1 \%$ das de lingüiça frescal de frango e de pernil ultrapassaram os padrões legais para nitrato (300 ppm) e nitrito ( $150 \mathrm{ppm}$ ) estabelecidos pela legislação.

Em termos tecnológicos, as oscilações nos teores de nitrato e nitrito entre produtores sugerem variações quanto à composição e à qualidade da matéria-prima e ingredientes adicionados, bem como entre os procedimentos operacionais em cada unidade de produção. As diferenças entre lotes possivelmente se devem a falhas nos procedimentos operacionais entre cada lote produzido em cada unidade de produção, demonstrando a inexistência do acompanha- mento do processo produtivo, que desde os anos 80 do século XX se baseia em ações preventivas e nos dias atuais em ações preditivas.

Quanto à qualidade dos produtos pesquisados, os dados indicam que tais produtos causam riscos de natureza química aos consumidores. A responsabilidade é do produtor, que precisa se adequar a um sistema de produção que se fundamente nas ferramentas de segurança alimentar. À vigilância sanitária cabem as orientações ao produtor sobre os procedimentos para eliminar, reduzir ou prevenir riscos à saúde decorrentes da produção, da circulação de bens e da prestação de serviços.

\section{5 - REFERÊNCIAS BIBLIOGRÁFICAS}

[1] ANJOS, A.C. e RIBEIRO, P. O nitrito em carnes curadas: vantagens, desvantagens e recursos tecnológicos para reduzir os níveis de nitrosaminas no bacon, Revista Higiene Alimentar, São Paulo, v. 8, n. 29, p. 8-13, 1994a.

[2] ANJOS, A.C. e RIBEIRO, P. Nitrito em carnes curadas. Revista Nacional da Carne, São Paulo, n. 227, 1994b.

[3] BRASIL, Ministério da Agricultura, Pecuária e Abastecimento (MAPA) - Instrução Normativa ${ }^{\circ} 4$. Anexo III - Regulamento Técnico de Identidade e Qualidade de Lingüiça. D.O.U., 05 de abril de 2000. Disponível na internet via www. URL: agricultura.gov.br/sda/dipoa. Acessado em janeiro de 2003.

[4] BRASIL. Secretaria de Vigilância Sanitária do Ministério da Saúde. Portaria $n^{\circ} 1004$, de 11 de dezembro de 1998, republicada no Diário Oficial da União de 22 de março de 1999. Aprova Regulamento Técnico: "Atribuição de função de aditivos, aditivos e seus limites máximos de uso para a categoria 8 - carne e produtos cárneos". Disponível em http://www.anvisa. gov.br/alimentos. Acessado em janeiro de 2003.

[5] FERRÃO, S.P.B.; SANTOS, W.L.M. \& VERSIANI, C.V. Determinação de nitritos em lingüiças frescais comercializadas em Belo Horizonte - M.G. Higiene Alimentar, São Paulo, v. 13, n. 61, abril/maio 1999.

[6] FLANDRIN, J.L.; MONTANARI, M. História da Alimentação, $2^{a}$ ed., São Paulo: Estação Liberdade, 1996.

[7] GRANER, M.; FONSECA, H.; BASSO, L. C. Composição química de salames nacionais. Ciência e Tecnologia de Alimentos. v. 3 (1), p. 48-57. Campinas - SP. 1983.

[8] HAVERY, D.C.; FAZIO, T. Human exposure to nitrosamines from foods. Fd. Technol., v. 39, p. 80-3, Jn. 1985.

[9] HIRSCHBRUCH, M.D.; TORRES, E.A.F.S.; ROVIELO, A.; RABAY, A. Natural X Seguro: Compilação de substâncias tóxicas naturalmente presentes nos alimentos. Higiene Alimentar, v. 13, n. 62, p. 28-33, Jun., 1999.

[10] LANARA (Laboratório Nacional de Referência Animal). Métodos Analíticos Oficiais para Controle de Produtos de Origem Animal e seus Ingredientes. Brasília: Ministério da Agricultura, 1981.v. 2. Métodos Físicos e Químicos.

[11] LARA, W.H.;TAKAHASHI, M.Y.; YABIKU, H.Y. Níveis de nitratos e nitritos em alimentos infantis. Rev. Inst. Adolfo Lutz 40 (2), p. 147-152, 1978. 
[12] LARA, W. H. ; TAKAHASHI, M. Y.; SILVEIRA, W. Determinação de nitrito e nitrato em conservas de carne. Rev. do Instituto Adolfo Lutz, São Paulo, 38 (2): 61- 66 p, 1989.

[13] LEITÃO, M.F.F. Microrganismos patogênicos na carne e derivados. Boletim do ITAL, Campinas, v. 59, p. $15-48,1978$

[14] LEITE, O.A. Aspectos físico-químicos de interesse higiênico-sanitário e tecnológico de lingüiças frescais. Niterói, 1989. 67 p. Dissertação de Mestrado em Medicina Veterinária. Faculdade de Veterinária, Universidade Federal Fluminense (UFF).

[15] MANHOSO, F.F.R.; RUDGE, A C. Aspectos microbiológicos, físico-químicos e histológicos das lingüiças tipo frescal comercializadas no município de Marília/SP. Higiene Alimentar, v. 13, n 61, p. 44, 1999.

[16] POPPER, I.; CARLOS, M.A.; FIGUEIREDO, B.; GARCIA, S.; PINTO, M.P.; SILVA, A.C.; SOUSA, I.F.; PRIMO, C.B.B.; BORGES, R. Avaliação da formulação de lingüiças tipo frescal coletadas no município de Londrina, quanto aos teores de gordura, proteína e água. In: Congresso Brasileiro de Ciência e Tecnologia de Alimentos, 17, 2000, Fortaleza, Resumos. Fortaleza. Anais: Ceará, 2000.

[17] SAS INSTITUTE INCORPORATION (Cary, NC, USA) The SAS for Windows. release 6.08. Cary, 1992.

[18] SECRETARIA DO ESTADO DE SAÚDE. Laudos de Análises do Laboratório Central de Saúde Pública - LACEN/DF. 2000.

[19] SCHVARTSMAN, S. Manual sobre intoxicações alimentares. Sociedade Brasileira de Pediatria. 47 p. Rio de Janeiro, 1990.

[20] SEBRANEK, J.G.; FOX, J.B. Nitrosamines. A Review. Journal Milk Food Technology. 36(2): 76-91, 1979.

[21] SGARBIERI, V.C. Alimentação e Nutrição - Fator de
Saúde e Desenvolvimento. São Paulo, 387 p. 1987.

[22] SHENOY, N.R.; CHOUHGULEY, A.S.U. Effect of certain plant phenolics on nitrosamine formation. J. Agric. Fd. Chem. v. 37, p. 721-725, 1989.

[23] SILVESTRE, M.P.C.; GLORIA, M.B.A. N-nitrosaminas não voláteis em alimentos. Uma revisão. Bol. sbCTA. Campinas, v. 23, n. 3-4, p. 209-19, 1989.

[24] SOFOS, J.N.; BUSTA, F.F. Alternatives to use nitrite as an antibotulinal agent. Food Technol., v. 34, p. 244-51, 1980.

[25] SOUZA, P.A.; FALEIROS, R.R.S.; SOUZA, H.B.A. Dosagem de nitrito e nitrato em produtos embutidos de carne. Alimentos e Nutrição, v. 2, p. 21-6, 1985.

[26] TAKAHASHI, G. Ingredientes e suas funções na fabricação de produtos cárneos. Revista Nacional da Carne. n. 199, ano XVII, p. 14-18. São Paulo, 1993.

[27] TAVARES, M.; ZANELATTO, A.M.; CARVALHO, J.B.; BACETTI, L.B.; TAKAHASHI, M.Y. e AUED, S. Determinação de nitratos e nitritos em lingüiça e outras conservas comercializadas na região metropolitana de São Paulo. Instituto Adolfo Lutz, v. 47, n. 1/2, p. 5-10, 1987.

[28] TOLEDO, M.C.F. Aditivos para alimentos: aspectos toxicológicos. Revista Nacional da Carne. n. 239, ano XXI, p. 42-43. São Paulo, 1997.

[29] VIEIRA, P. Pesquisa e desenvolvimento driblam os defeitos mais comuns em embutidos, Rev. Nacional da Carne, São Paulo, n. 273, ano 35, p. 80-84, 1999.

[30] WOOTTON, M. Food toxicology - an overview. In: Wahlqvist, M.L. et al. - Food and Health - Issues and Directions. London: Jonh Libbey, p. 35-38, 1987.

[31] XIMENES, M.I.N.; RODRIGUES, G.M.; MARQUES, S.R.M.N. Teor residual de nitrato e nitrito em produtos cárneos curados, comercializados no Distrito Federal. In: Revista de Saúde do Distrito Federal, v. 9, n. 2, abr./jun. 1998. 